\section{BRAZIULIAN JOURNAL}

OF MEDICAL AND BIOLOGICAL RESHARCH

www.bjournal.com.br
ISSN 0100-879X

Volume 43 (9) 812-913 September 2010

BIOMEDICAL SCIENCES

AND

CLINICAL INVESTIGATION

Braz J Med Biol Res, September 2010, Volume 43(9) 853-859

doi: 10.1590/S0100-879X2010007500078

Lipopolysaccharide-induced expression of cell surface receptors and cell activation of neutrophils and monocytes in whole human blood

N.E. Gomes, M.K.C. Brunialti, M.E. Mendes, M. Freudenberg, C. Galanos and R. Salomão

The Brazilian Journal of Medical and Biological Research is partially financed by

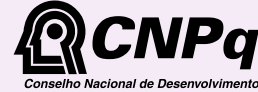

Ministério da Ciência e Tecnologia

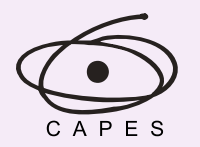

Ministério da Educação

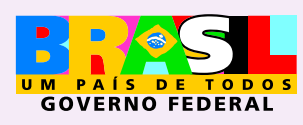

GOVERNO FEDERAL
TFAPESP

Institutional S ponsors

Hotsite of proteomics metabolomics developped by:$$
\text { อ }
$$

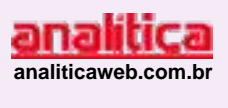




\title{
Lipopolysaccharide-induced expression of cell surface receptors and cell activation of neutrophils and monocytes in whole human blood
}

\author{
N.E. Gomes ${ }^{1}$, M.K.C. Brunialti ${ }^{1}$, M.E. Mendes ${ }^{1}$, M. Freudenberg ${ }^{2}$, \\ C. Galanos ${ }^{2}$ and R. Salomão ${ }^{1}$ \\ ${ }^{1}$ Disciplina de Infectologia, Universidade Federal de São Paulo, São Paulo, SP, Brasil \\ ${ }^{2}$ Max-Planck-Institute for Immunobiology, Freiburg, Germany
}

\begin{abstract}
Lipopolysaccharide (LPS) activates neutrophils and monocytes, inducing a wide array of biological activities. LPS rough (R) and smooth (S) forms signal through Toll-like receptor 4 (TLR4), but differ in their requirement for CD14. Since the R-form LPS can interact with TLR4 independent of CD14 and the differential expression of CD14 on neutrophils and monocytes, we used the S-form LPS from Salmonella abortus equi and the R-form LPS from Salmonella minnesota mutants to evaluate LPS-induced activation of human neutrophils and monocytes in whole blood from healthy volunteers. Expression of cell surface receptors and reactive oxygen species (ROS) and nitric oxide (NO) generation were measured by flow cytometry in whole blood monocytes and neutrophils. The oxidative burst was quantified by measuring the oxidation of 2', 7 '-dichlorofluorescein diacetate and the NO production was quantified by measuring the oxidation of 4-amino-5-methylamino-2',7'-difluorofluorescein diacetate. A small increase of TLR4 expression by monocytes was observed after $6 \mathrm{~h}$ of LPS stimulation. Monocyte CD14 modulation by LPS was biphasic, with an initial 30\% increase followed by a $40 \%$ decrease in expression after $6 \mathrm{~h}$ of incubation. Expression of CD11b was rapidly up-regulated, doubling after 5 min on monocytes, while down-regulation of CXCR2 was observed on neutrophils, reaching a $50 \%$ reduction after $6 \mathrm{~h}$. LPS induced low production of ROS and NO. This study shows a complex LPS-induced cell surface receptor modulation on human monocytes and neutrophils, with up- and down-regulation depending on the receptor. R- and S-form LPS activate human neutrophils similarly, despite the low CD14 expression, if the stimulation occurs in whole blood.
\end{abstract}

Key words: Lipopolysaccharide; Neutrophils; Monocytes; Cell surface receptors; Reactive oxygen species; Nitric oxid

\section{Introduction}

Interaction between the innate immune system and microbial constituents is the basis of pathogen recognition and induced cellular activation (1). Lipopolysaccharide (LPS), present in Gram-negative bacteria, is a primary target for the recognition of bacteria, and elicits many of their pathogenic effects as well as a protective immune response (2). The interaction between LPS and cells of the innate immune system, such as neutrophils and monocytes, triggers an inflammatory response, driven to control the infection process, but that also may trigger the pathophysiological response leading to severe sepsis and septic shock (3).

LPS-induced cell activation is mediated by the Toll-like receptor 4 (TLR4) (4), and is dependent on LPS-binding protein and the CD14 receptor [as membrane-bound (mCD14) or soluble (sCD14) protein] (5). Signal transduction by TLRs requires association with myeloid differentiation protein 2 (6) and occurs by two pathways, one depending on the myeloid differentiation primary response gene (88) (MyD88) and the other MyD88-independent. The former induces activation of mitogen-activated protein kinases and translocation of transcriptional factor $\mathrm{kB}(\mathrm{NF}-\mathrm{kB})$. The MyD88-independent signal activates interferon regulatory factor 3 and also NF-kB, although on a late basis (7). Both signaling pathways are involved in oxidative burst and

Correspondence: R. Salomão, Rua Pedro de Toledo, 781, 15aandar, 04039-032 São Paulo, SP, Brasil.

Fax: +55-11-5081-5394/5579-8226. E-mail: rsalomao@unifesp.br

Received March 22, 2010. Accepted July 26, 2010. Available online August 13, 2010. Published September $13,2010$. 
induction of nitric oxide (NO) $(8,9)$.

LPS-induced cell activation in whole blood has the advantage of preserving the microenvironment of LPS and cell interaction as it occurs in vivo; however, studies of the effects of LPS on different cell populations in whole blood are scarce. Flow cytometry permits the study of the effects of LPS in whole blood at the cellular level $(10,11)$. Macrophages are considered to be the primary targets of LPS, and neutrophils have also been reported as highly LPS-responsive cells. In the present study, we evaluated the modulation of cell surface receptors, oxidative burst and NO production by neutrophils and monocytes in whole blood of human volunteers.

Recently, it has been shown that the rough (R)-form LPS can interact with TLR4 without CD14 $(12,13)$. Re-form LPS (lipid A + two 3-deoxy-D-manno-2-octurosonic acid residues), but not the smooth (S)-form LPS, can induce tumor necrosis factor-alpha (TNF- $\alpha$ ) responses also in the absence of CD14 (12). R-form LPS was a potent activator of mast cells (that lack CD14), while S-form LPS was practically devoid of stimulatory activity (13). Since human neutrophils either lack or express low amounts of mCD14, it became important to study if LPS-induced neutrophil activation is different when stimulated by S- or R-form LPS. For this reason, we used both LPS types in the present study.

\section{Material and Methods}

\section{Reagents}

S-form LPS from Salmonella abortus equi and R-form LPS from Salmonella minnesota mutants (R595(Re)) were extracted from parent bacteria and purified as previously described (14).

The following monoclonal antibodies were used: CD66b-fluorescein isothiocyanate (FITC), clone G1OF5; CD14-peridinin-chlorophyll-protein (PerCP), clone M8P9; CD11b-allophycocyanin (APC), clone D12; CD11c-APC, clone S-HCL-3; CD15-APC, clone HI98, and CXCR2-APC, clone 6C6 were obtained from BD Biosciences (USA). TLR2-phycoerythrin (PE), clone TL2.1 and TLR4-PE, clone HTA125 were obtained from eBioscience (USA). p50-PE, clone sc-8414 and p65-PE, clone sc-8008 were obtained from Santa Cruz Biotechnology (USA).

\section{Healthy volunteers \\ The study was approved by the Universidade Federal de São Paulo Ethics Committee (process No. 1304/05) and written informed consent was obtained from all volunteers. Blood samples from 21 volunteers (mean age: $28 \pm 7$ years, $38 \%$ males) were used. \\ Cell surface receptor expression in whole blood in response to R- or S-form LPS}

Expression of cell surface receptors on monocytes and neutrophils was determined in whole blood as previously described (15). Cells were stained with $6 \mu \mathrm{L}$ CD14-PerCP and $5 \mu \mathrm{L}$ CD66b-FITC in order to identify monocytes and neutrophils, respectively. For kinetics, the cells were also stained with $20 \mu \mathrm{L}$ TLR4-PE and $2 \mu \mathrm{L}$ CD11b-APC (tube 1), $20 \mu \mathrm{L}$ TLR2-PE and $2 \mu \mathrm{L}$ CD11C-APC (tube 2), or 2 $\mu \mathrm{L}$ CXCR2-APC (tube 3). A dose-response assay was performed with CD11b-APC.

Event acquisition and analyses were performed using the CellQuest software (BD Biosciences) and an FACSCalibur 4-color flow cytometer (BD Biosciences). Monocyte analyses were carried out using forward and side scatter parameters combined with CD14-positive- and CD66b-negative-stained cells, and neutrophil analyses were performed using forward and side scatter parameters combined with CD66b-positive- and CD14-negative-stained cells. Surface receptor expression was measured as the geometric mean fluorescence intensity (GMFI).

\section{Analysis of oxidative burst in whole blood after stimulation with R- or S-form LPS}

The oxidative burst was quantified by measuring the oxidation of 2',7'-dichlorofluorescein diacetate (DCFH-DA, Sigma, USA) in whole blood as previously described (16). Neutrophils in whole blood were characterized by side scatter and forward scatter parameters and negativity for CD14 and monocytes was characterized by side scatter and forward scatter parameters and positive staining for CD14. Reactive oxygen species (ROS) generation is reported in histograms and expressed as the GMFI.

\section{Analysis of NO production in whole blood after stimulation with R- or S-form LPS}

NO production was quantified by measuring the oxidation of 4-amino-5-methylamino-2',7'-difluorofluorescein diacetate (Invitrogen, USA) in whole blood by the method of Zelnickova et al. (17), modified. Cells were stained with $5 \mu \mathrm{L}$ CD14-PE and $5 \mu \mathrm{L}$ CD15-FITC for monocyte and neutrophil identification, respectively. NO generation is reported in histograms and expressed as the GMFI.

\section{Statistical analysis}

Data are reported as means \pm SEM and were compared by analysis of variance (ANOVA) and the post hoc Tukey honestly significant difference (HSD) test. The software used was SPSS 13.0 for Windows (USA).

\section{Results}

\section{LPS-induced modulation of the expression of cell surface receptors in whole blood}

Induction of CD11b in monocytes and neutrophils by LPS: dose-response. Whole blood samples were stimulated for 30 min with different amounts of R- or S-form LPS (1$100 \mathrm{ng} / \mathrm{mL}$ ) and the expression of CD11b on monocytes and neutrophils was determined by fluorescence-activating 
cell sorting (FACS). The 100-ng LPS/mL dose was chosen and used for stimulation throughout the study (data not shown).

Kinetics of LPS-induced modulation of surface receptor expression on monocytes. The modulation of receptor expression on monocytes was monitored between 5 min and $24 \mathrm{~h}$ after the addition of LPS to whole blood cultures. Although no changes in TLR4 expression were observed by 180 min, a significant up-regulation by both R- and Sform LPS was seen after $6 \mathrm{~h}$ of culture $(P=0.039$; Figure $1 \mathrm{~A}$ ), with a return to normal after $24 \mathrm{~h}$ (data not shown). No changes in TLR2 expression were detectable during the observation period (data not shown). CD14 expression was increased after $15-30 \min (P=0.034$ and $P=0.050)$ of stimulation, returned to normal levels at $180 \mathrm{~min}$ and decreased after $6 \mathrm{~h}(\mathrm{P}<0.001$; Figure $1 \mathrm{~B})$, a condition that persisted up to the end of the 24-h observation period. Increased CD11b expression was observed as early as 5 min after the addition of LPS and was highest after $6 \mathrm{~h}$ of
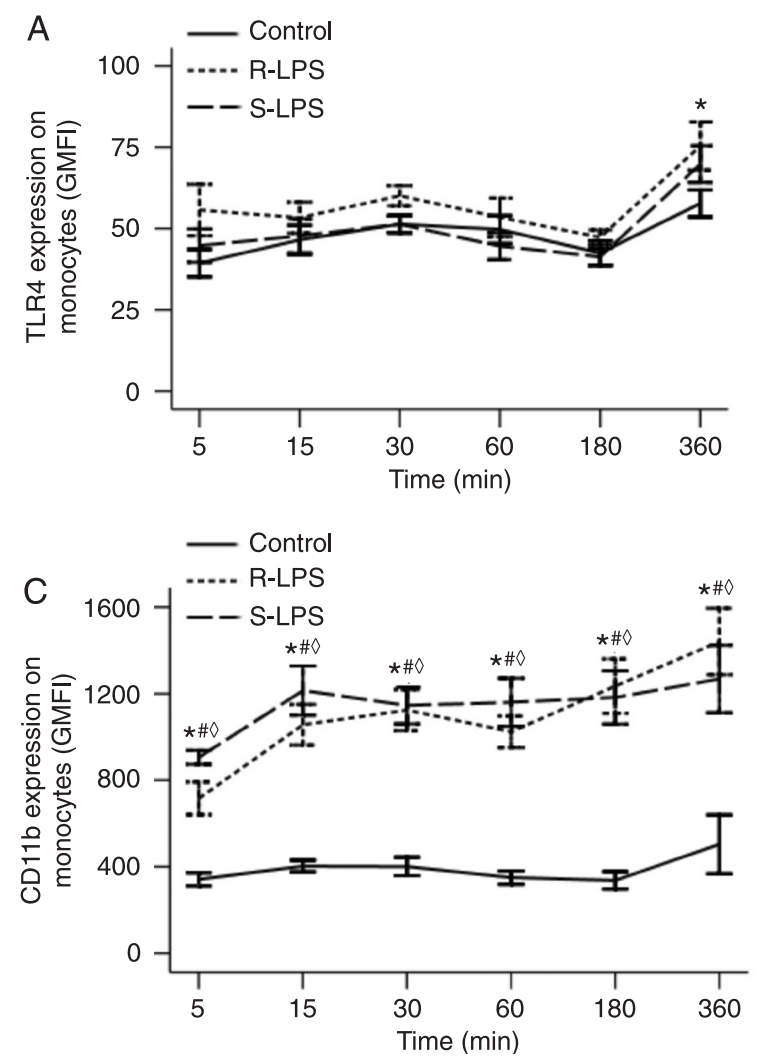

incubation (Figure 1C), with similar effects for both LPS forms. R- and S-form LPS-induced CD11c expression on monocytes reached no statistical significance compared to control (Figure 1D).

Kinetics of LPS-induced modulation of surface receptor expression on neutrophils. The modulation of receptor expression on neutrophils was monitored between 5 min and $24 \mathrm{~h}$ after the addition of LPS to whole blood cultures. The expression of TLR2 and TLR4 was not modulated by R- or S-form LPS (data not shown). CD14 surface expression on neutrophils was only marginal compared to that on monocytes. Thus, human neutrophils have little or no $\mathrm{mCD} 14$ on their surface, and its expression was not induced by either R- or S-form LPS (data not shown).

Both LPS forms induced a decrease of CXCR2 expression on neutrophils, already present after 15 min and observed throughout the $6 \mathrm{~h}$ of the experiment (Figure 2A).

CD66b expression was significantly up-regulated by both $\mathrm{R}$ - and S-form LPS $(\mathrm{P}=0.028$ and $\mathrm{P}=0.006$, after 3
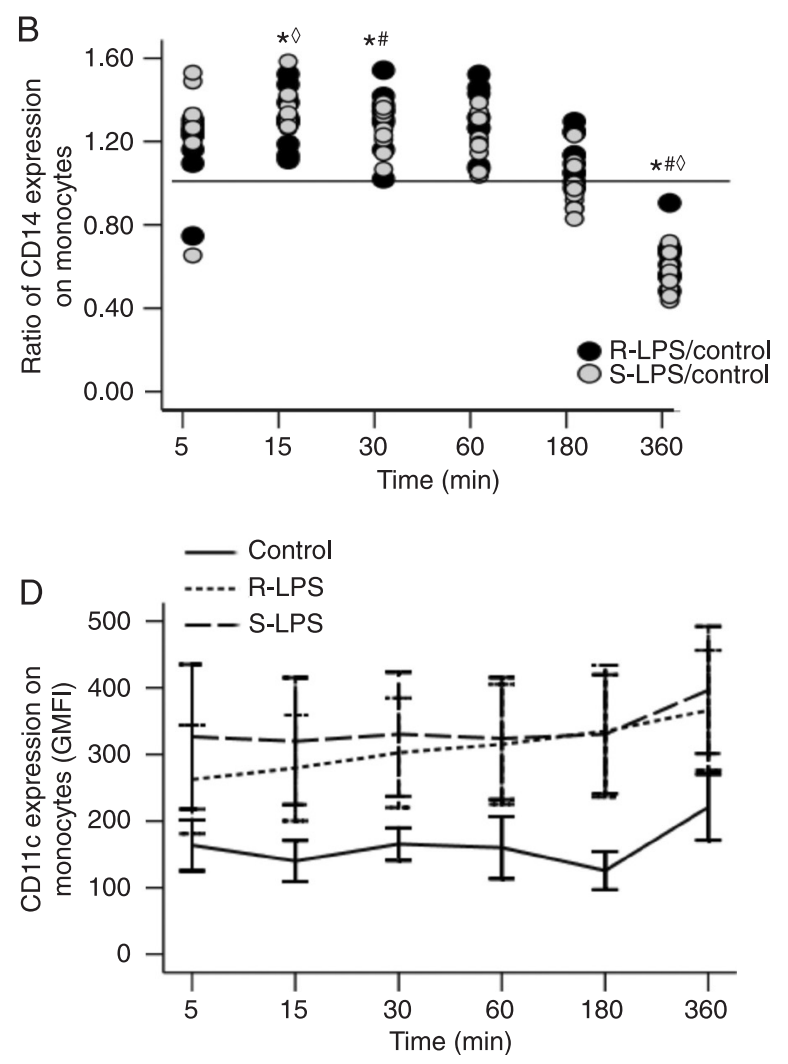

Figure 1. Expression of cell surface receptors on monocytes in whole blood after incubation with medium (control) or with $100 \mathrm{ng} / \mathrm{mL}$ rough (R)- or smooth (S)-form lipopolysaccharide (LPS). $A, C$, and $D$, Monocytes were gated based on forward and side scatter parameters and positive staining for CD14. The cell surface receptor expression was measured as geometric mean fluorescence intensity $(\mathrm{GMFI})$ and is reported as means \pm SEM for each time. $B$, Monocytes were gated based on forward and side scatter parameters and CD14 expression is represented as the ratio of CD14 expression between stimulated cells and controls. A, Results of TLR4 expression obtained from 4 individuals. $B$, Results of CD14 expression obtained from 10 healthy volunteers. $C$, Results of CD11b expression obtained from 5 individuals. $D$, Results of CD11c expression obtained from 4 individuals. ${ }^{*} \mathrm{P} \leq 0.05$ for group comparison (ANOVA), ${ }^{\ominus P}$ $\leq 0.05$ for S-form LPS versus control (Tukey post hoc test) and ${ }^{\#} \mathrm{P} \leq 0.05$ for R-form LPS versus control (Tukey post hoc test). 

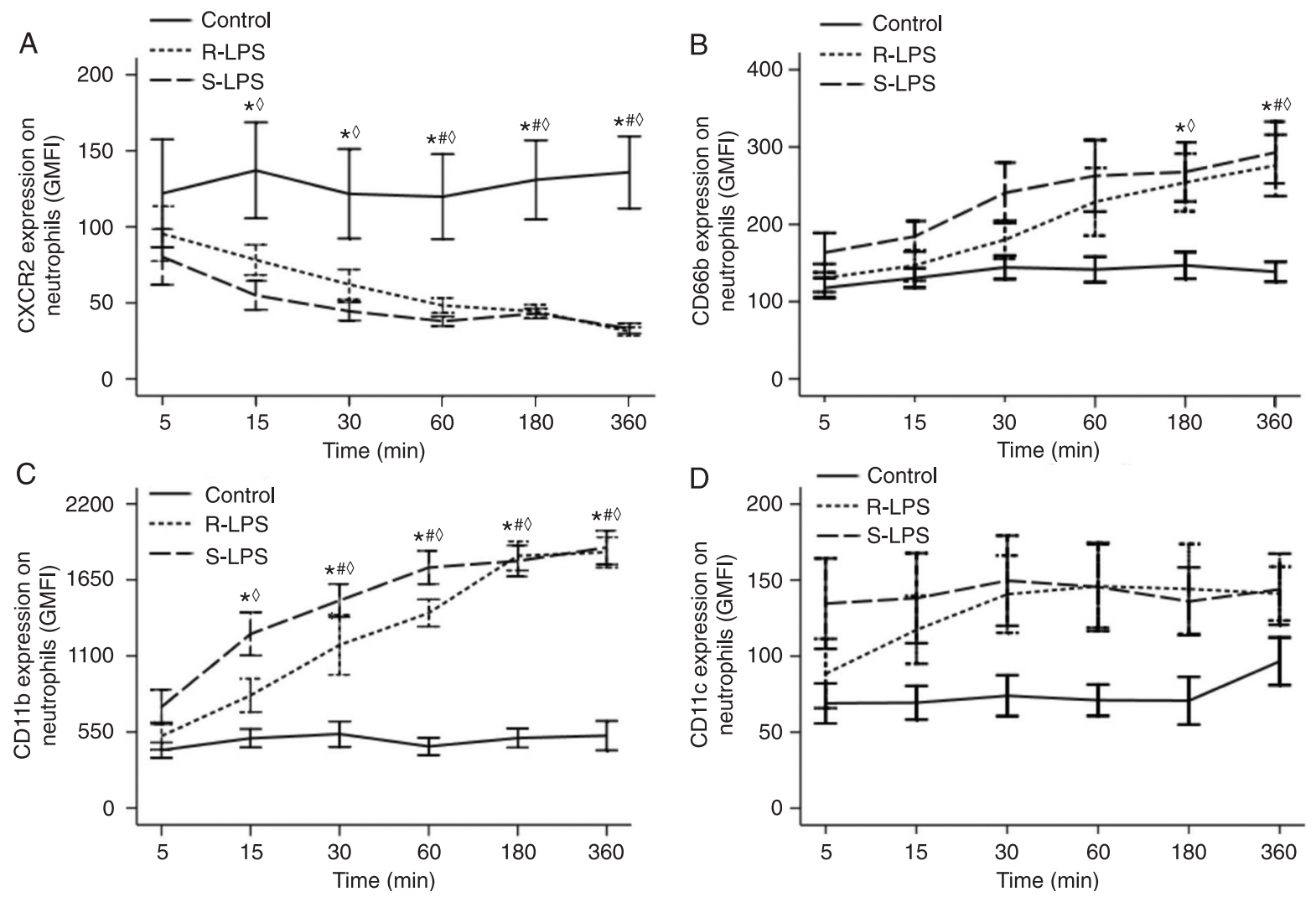

Figure 2. Expression of cell surface receptors on neutrophils in whole blood after incubation with medium (control) or with $100 \mathrm{ng} /$ $\mathrm{mL}$ rough (R)- or smooth (S)-form lipopolysaccharide (LPS). $A, C$, and $D$, Neutrophils were gated based on forward and side scatter parameters and positive staining for CD66b. The cell surface receptor expression was measured as geometric mean fluorescence intensity (GMFI) and is reported as means \pm SEM for each time. $B$, Neutrophils were gated based on forward and side scatter parameters and CD66b expression was measured as GMFI and is reported as means \pm SEM for each time. $A$, Results of CXCR2 expression obtained from 6 individuals. $B$, Results of CD66b expression obtained from 9 individuals. $C$, Results of CD11b expression obtained from 4 individuals. $D$, Results of CD11c expression obtained from 4 individuals. ${ }^{*} \mathrm{P} \leq 0.05$ for group comparison (ANOVA), ${ }^{\natural} \mathrm{P} \leq 0.05$ for S-form LPS versus control (Tukey post hoc test) and ${ }^{\#} \mathrm{P} \leq 0.05$ for R-form LPS versus control (Tukey post hoc test).

$\mathrm{h}$ and $6 \mathrm{~h}$ of stimulation, respectively, Figure 2B). S-form LPS seems to have an earlier effect in inducing CD66b expression (Figure 2B). CD66b expression on stimulated cells remained elevated up to $24 \mathrm{~h}$ of incubation (data not shown).

CD11b expression on neutrophils, similar to that on monocytes, was rapidly up-regulated by 15 min of stimulation, increased gradually with time (Figure 2C), persisting at an elevated level up to $24 \mathrm{~h}$ of stimulation (data not shown). When the Tukey test was performed, both LPS forms showed activity. In contrast, the expression of CD11c on neutrophils was low and did not significantly increase after blood was cultured with R- or S-form LPS (Figure 2D).

\section{LPS-induced production of ROS and NO by monocytes and neutrophils in whole blood}

A dose-dependent production of ROS was generated in monocytes and neutrophils within $30 \mathrm{~min}$ when whole blood samples were stimulated with LPS. No significant differences in ROS generation activity were observed between the two LPS forms (Figure $3 \mathrm{~A}$ and $\mathrm{B}$ ). A significant induction of $\mathrm{NO}$ was observed in monocytes (Figure 4A), but not in neutrophils (Figure $4 \mathrm{~B}$ ) after 30 min of stimulation with $100 \mathrm{ng} / \mathrm{mL} R$ - and S-form LPS $(P=0.019)$.

\section{Discussion}

We investigated the modulation of a wide range of cell surface receptors on human monocytes and neutrophils involved in bacterial recognition, chemotaxis, and cell-tocell interactions, in whole blood of human volunteers using the S- and R-forms of LPS.

In agreement with numerous other studies we show that not only monocytes, but also neutrophils, express the signaling receptor for LPS, TLR4 (11). However, in contrast to some reports $(18,19)$, we observed no down-regulation of 
TLR4 on monocytes during the initial period of stimulation (up to $3 \mathrm{~h}$ after LPS), but rather a weak, transient increase at $6 \mathrm{~h}$ after LPS. In addition, we found no changes in TLR4 expression in LPS-stimulated neutrophils. We also investigated the impact of LPS activation on the expression of TLR2 on both cell types. No major changes in TLR2 levels on the surface of monocytes and neutrophils were observed when whole blood samples were stimulated with LPS up to $24 \mathrm{~h}$.

While the expression of the LPS-binding co-receptor CD14 on monocytes has been well documented, the presence of CD14 on neutrophils is not so clear. Some investigators claim that CD14 is expressed in polymorphonuclear neutrophils, although to a lesser extent in monocytes (18), and a positive modulation of CD14 expression on neutrophils by LPS has been reported (20). FACS analysis of the present data showed that the levels of CD14 on unstimulated neutrophils were marginal or absent and, in agreement with Wright et al. (21), not affected by LPS stimulation. This absence of significant amounts of CD14 is also indirectly supported by results of an earlier study (22), in which only $\mathrm{R}$-form LPS preparations elicited oxidative responses in isolated neutrophils, while the S-form LPS was virtually inactive. Since it is known today that only the R-form LPS can activate TLR4-positive cells independent of CD14 (12), retrospectively the inability of the S-form LPS to activate neutrophils under serum-free conditions (22) can be explained by the absence of CD14 on human neutrophils.

As previously shown (23), LPS modulated the expression of $\mathrm{mCD} 14$ on monocytes. The rapid increase of $\mathrm{mCD} 14$ expression (15 and 30 min after the addition of LPS) was followed by a strong decrease of expression between 6 and $24 \mathrm{~h}$ later compared to control. This kinetics is not fully consistent with finding reported by others. Some investigators (24) did not detect a change in response of peripheral blood mononuclear cells (PBMC) after the addition of the S-form LPS after $120 \mathrm{~min}$, others (25) observed an initial decrease followed by a sharp increase after $24 \mathrm{~h}$ of PBMC incubation, while still others (23) described a positive modulation of CD14 on whole blood monocytes during $4 \mathrm{~h}$ of incubation. The finding of LPS-induced down-regulation of CD14 raises the question of whether this effect might be involved in the down-regulation of the pro-inflammatory response during re-exposure of target cells to LPS. Here, however, the concomitant unsuppressed or even enhanced production of anti-inflammatory proteins (26) had to be explained.

We show here that both LPS forms substantially upregulated the expression of $\mathrm{CD} 11 \mathrm{~b}$ on monocytes and neutrophils. CD11b up-regulation persisted during the 6 $h$ of LPS stimulation on monocytes and neutrophils, in contrast to Haugen et al. (27), who found both up- and down-regulation of its expression. These discrepancies may be due to different experimental conditions. CD11 molecules (a, b, c, d)/CD18 $\beta 2$ integrins are important for cell adhesion to the endothelium (28) and CD11b/CD18 has
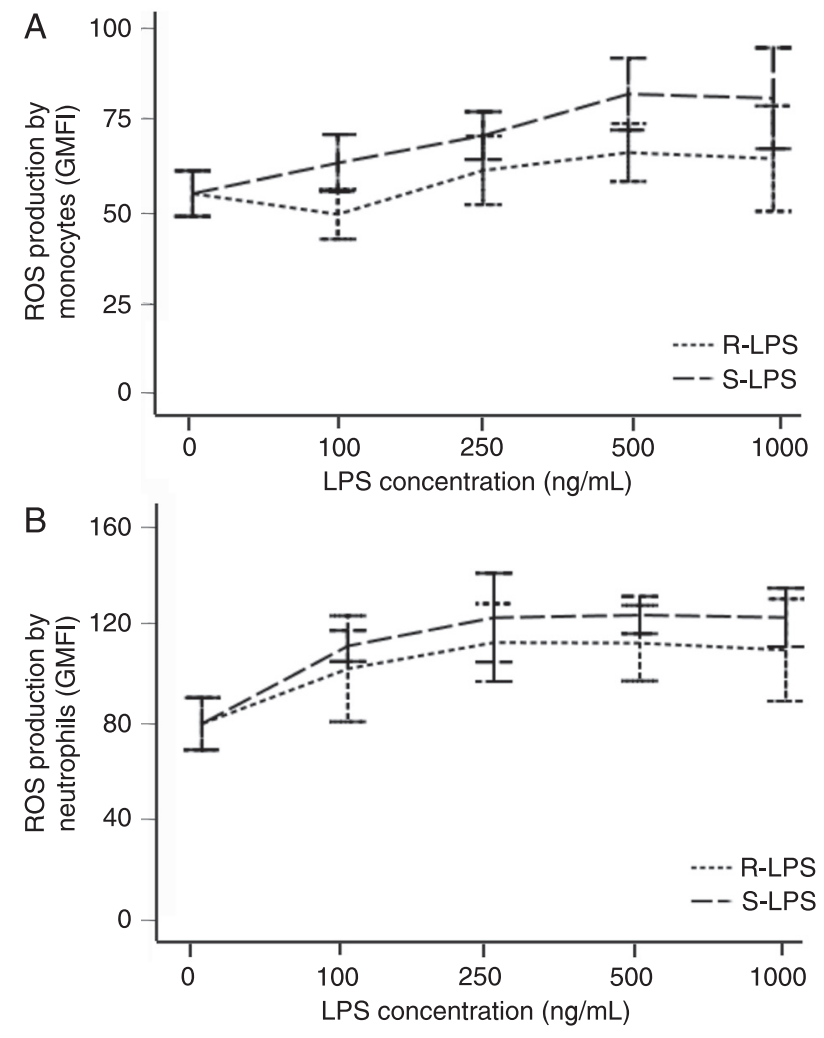

Figure 3. Production of reactive oxygen species (ROS) by monocytes (A) and neutrophils (B) in response to different concentrations of rough (R)- or smooth (S)-form lipopolysaccharide (LPS, 0 , $100,250,500$, and $1000 \mathrm{ng} / \mathrm{mL}$ ) applied for $30 \mathrm{~min}$. ROS production is reported as geometric mean fluorescence intensity (GMFI) and is reported as means \pm SEM for each concentration. Results obtained from 3 individuals.

$A$

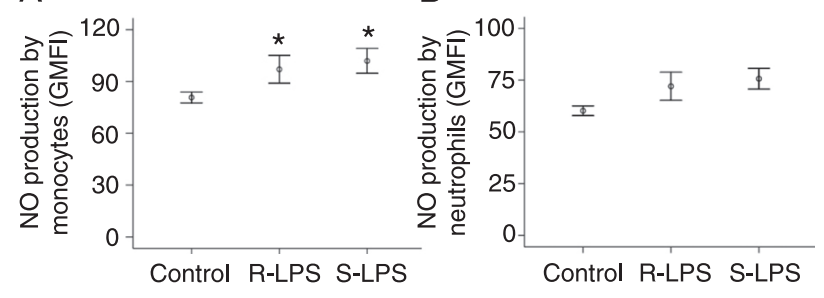

Figure 4. Nitric oxide (NO) production by monocytes and neutrophils after incubation with medium (control) or $100 \mathrm{ng} / \mathrm{mL}$ rough (R)- or smooth (S)-form lipopolysaccharide (LPS) for $30 \mathrm{~min}$. Monocytes (A) were gated based on forward and side scatter parameters and positive CD14 staining, and neutrophils (B) based on forward and side scatter parameters and positive staining for CD15. NO production was measured as geometric mean fluorescence intensity (GMFI) of benzotriazolic derivate and is reported as means \pm SEM for each stimulus. Results obtained from 7 individuals. ${ }^{*} \mathrm{P}<0.05$ compared to control (ANOVA and Tukey post hoc test). 
already been suggested to be an LPS receptor in human macrophages (29). Zhou et al. (30) suggested that LPS can amplify its response because of CD11b. Recently, CD11b/ CD18 was found to play a significant role in the optimal LPS response (31). We found a transient association between CD14 and CD11b/CD18 expression after LPS stimulation on monocytes, as previously reported for neutrophils (32), that may indicate an initial regulation driven to optimize LPS recognition and signaling.

CD66b, another protein involved in cell migration, was strongly induced by both LPS forms on the neutrophil surface. No studies have evaluated the modulation of this receptor by LPS on the neutrophil surface.

In agreement with previous studies (33), we found that LPS induced down-regulation of the chemokine receptor CXCR2 on neutrophils. The decrease of CXCR2 expression may be part of the negative regulatory effects by the host to limit inflammation.

Altogether, the enhanced co-expression of CD11b and CD14 on monocytes might indicate an up-regulation of recognizing and signaling receptors in the initial response to LPS, while the later decrease in CD14 expression and the persistently increased expression of CD11b might favor adhesion properties. The enhanced expression of CD66b and CD11b on neutrophils also seems to indicate an enhanced capacity of migration and adhesion, which somehow contrasts with the decreased expression of CXCR2.

Despite the good results obtained with monocytes and neutrophils in dose-response assays, ROS production by LPS was not consistent in all experiments and it is not a consensus in the literature (with some studies reporting little production, and others strong production). Interestingly, Kapp et al. (22), using lucigenin-dependent chemiluminescence for the detection of oxygen radicals, showed that

\section{References}

1. Janeway CA Jr, Medzhitov R. Innate immune recognition. Annu Rev Immunol 2002; 20: 197-216.

2. O'Brien AD, Rosenstreich DL, Scher I, Campbell GH, MacDermott RP, Formal SB. Genetic control of susceptibility to Salmonella typhimurium in mice: role of the LPS gene. $J$ Immunol 1980; 124: 20-24.

3. Salomao R, Martins PS, Brunialti MK, Fernandes ML, Martos LS, Mendes ME, et al. TLR signaling pathway in patients with sepsis. Shock 2008; 30 (Suppl 1): 73-77.

4. Poltorak A, He X, Smirnova I, Liu MY, Van Huffel C, Du X, et al. Defective LPS signaling in $\mathrm{C} 3 \mathrm{H} / \mathrm{HeJ}$ and $\mathrm{C} 57 \mathrm{BL} / 10 \mathrm{ScCr}$ mice: mutations in TIr4 gene. Science 1998; 282: 20852088.

5. Wright SD, Ramos RA, Tobias PS, Ulevitch RJ, Mathison JC. CD14, a receptor for complexes of lipopolysaccharide (LPS) and LPS binding protein. Science 1990; 249: 1431-1433.

6. Kimoto M, Nagasawa K, Miyake K. Role of TLR4/MD-2 and RP105/MD-1 in innate recognition of lipopolysaccharide. Scand J Infect Dis 2003; 35: 568-572. only the R-form LPS was able to induce strong activation of isolated neutrophils. Myhre et al. (34) suggested that DCFH cannot detect all ROS production, and that various methods should be used for ROS identification. We may have missed this activity by the detection method used, and found a weak and similar ROS generation with R-and S-form LPS by DCFH oxidation.

R- and S-form LPS induced NO production by monocytes but not by neutrophils after 30 min of stimulation in whole blood. This finding agrees with a previous report that showed no stimulation of neutrophil production by S-, Ra- or Re-form LPS at any dose or time used (35). The low LPS-induced production of NO in these experiments may reflect the difficulties in detecting $\mathrm{NO}$ activity in human cells since LPS is one of the main inducers of NO synthase in inflammatory cells (36).

In the present study we showed that, despite their differential requirement for CD14 help, S- and R-form LPS activate cells with differential CD14 expression - monocytes and neutrophils - with similar strength and kinetics, if the stimulation is applied to whole blood. Thus, S- and R-form LPS were highly comparable in their property to modulate different surface receptors and to induce an oxidative burst and NO production in monocytes and neutrophils. Since larger amounts of soluble CD14 (sCD14) are known to substitute membrane-bound CD14 (mCD14) during activation of cells with LPS, our data show that the levels of sCD14 in plasma of healthy humans fully compensate for the shortage of mCD14 in circulating neutrophils.

\section{Acknowledgments}

Research supported by FAPESP (\#2006/58744-1).
7. Takeda K, Akira S. Toll-like receptors in innate immunity. Int Immunol 2005; 17: 1-14.

8. Beutler B, Rietschel ET. Innate immune sensing and its roots: the story of endotoxin. Nat Rev Immunol 2003; 3: 169-176.

9. Kim JW, Kim C. Inhibition of LPS-induced NO production by taurine chloramine in macrophages is mediated though Ras-ERK-NF-kappaB. Biochem Pharmacol 2005; 70: 13521360.

10. Salomao R, Brunialti MK, Kallas EG, Martins PS, Rigato $\mathrm{O}$, Freudenberg M. Lipopolysaccharide-cell interaction and induced cellular activation in whole blood of septic patients. J Endotoxin Res 2002; 8: 371-379.

11. Martins PS, Brunialti MK, Martos LS, Machado FR, Assuncao MS, Blecher S, et al. Expression of cell surface receptors and oxidative metabolism modulation in the clinical continuum of sepsis. Crit Care 2008; 12: R25.

12. Jiang Z, Georgel P, Du X, Shamel L, Sovath S, Mudd S, et al. CD14 is required for MyD88-independent LPS signaling. 
Nat Immunol 2005; 6: 565-570.

13. Huber M, Kalis C, Keck S, Jiang Z, Georgel P, Du X, et al. R-form LPS, the master key to the activation of TLR4/MD2-positive cells. Eur J Immunol 2006; 36: 701-711.

14. Galanos C, Luderitz O, Westphal O. Preparation and properties of a standardized lipopolysaccharide from Salmonella abortus equi (Novo-Pyrexal). Zentralbl Bakteriol Orig A 1979; 243: 226-244.

15. Brunialti MK, Martins PS, Barbosa de $\mathrm{CH}$, Machado FR, Barbosa LM, Salomao R. TLR2, TLR4, CD14, CD11B, and CD11C expressions on monocytes surface and cytokine production in patients with sepsis, severe sepsis, and septic shock. Shock 2006; 25: 351-357.

16. Martins PS, Kallas EG, Neto MC, Dalboni MA, Blecher $\mathrm{S}$, Salomao R. Upregulation of reactive oxygen species generation and phagocytosis, and increased apoptosis in human neutrophils during severe sepsis and septic shock. Shock 2003; 20: 208-212.

17. Zelnickova P, Faldyna M, Ondracek J, Kovaru H, Kovaru F. Ontogeny of reactive nitrogen species production by blood phagocytes in pigs. Physiol Res 2008; 57: 81-88.

18. Kurt-Jones EA, Mandell L, Whitney C, Padgett A, Gosselin $\mathrm{K}$, Newburger PE, et al. Role of Toll-like receptor 2 (TLR2) in neutrophil activation: GM-CSF enhances TLR2 expression and TLR2-mediated interleukin 8 responses in neutrophils. Blood 2002; 100: 1860-1868.

19. Husebye $H$, Halaas $O$, Stenmark $H$, Tunheim $G$, Sandanger $\mathrm{O}$, Bogen B, et al. Endocytic pathways regulate Toll-like receptor 4 signaling and link innate and adaptive immunity. EMBO J 2006; 25: 683-692.

20. Wagner C, Deppisch R, Denefleh B, Hug F, Andrassy K, Hansch GM. Expression patterns of the lipopolysaccharide receptor CD14, and the FCgamma receptors CD16 and CD64 on polymorphonuclear neutrophils: data from patients with severe bacterial infections and lipopolysaccharideexposed cells. Shock 2003; 19: 5-12.

21. Wright SD, Ramos RA, Hermanowski-Vosatka A, Rockwell P, Detmers PA. Activation of the adhesive capacity of CR3 on neutrophils by endotoxin: dependence on lipopolysaccharide binding protein and CD14. J Exp Med 1991; 173: 1281-1286.

22. Kapp A, Freudenberg M, Galanos C. Induction of human granulocyte chemiluminescence by bacterial lipopolysaccharides. Infect Immun 1987; 55: 758-761.

23. Moller AS, Ovstebo R, Haug KB, Joo GB, Westvik AB, Kierulf $P$. Chemokine production and pattern recognition receptor (PRR) expression in whole blood stimulated with pathogenassociated molecular patterns (PAMPs). Cytokine 2005; 32: 304-315.

24. Flo TH, Halaas O, Torp S, Ryan L, Lien E, Dybdahl B, et al.
Differential expression of Toll-like receptor 2 in human cells. J Leukoc Biol 2001; 69: 474-481.

25. Landmann R, Reber AM, Sansano S, Zimmerli W. Function of soluble CD14 in serum from patients with septic shock. $J$ Infect Dis 1996; 173: 661-668.

26. Foster SL, Hargreaves DC, Medzhitov R. Gene-specific control of inflammation by TLR-induced chromatin modifications. Nature 2007; 447: 972-978.

27. Haugen TS, Skjonsberg OH, Nakstad B, Lyberg T. Modulation of adhesion molecule profiles on alveolar macrophages and blood leukocytes. Respiration 1999; 66: 528-537.

28. Mazzone A, Ricevuti G. Leukocyte CD11/CD18 integrins: biological and clinical relevance. Haematologica 1995; 80: 161-175.

29. Wright SD, Jong MT. Adhesion-promoting receptors on human macrophages recognize Escherichia coli by binding to lipopolysaccharide. J Exp Med 1986; 164: 1876-1888.

30. Zhou X, Gao XP, Fan J, Liu Q, Anwar KN, Frey RS, et al. LPS activation of Toll-like receptor 4 signals CD11b/CD18 expression in neutrophils. Am J Physiol Lung Cell Mol Physiol 2005; 288: L655-L662.

31. Perera PY, Mayadas TN, Takeuchi O, Akira S, Zaks-Zilberman M, Goyert SM, et al. CD11b/CD18 acts in concert with CD14 and Toll-like receptor (TLR) 4 to elicit full lipopolysaccharide and taxol-inducible gene expression. J Immunol 2001; 166: 574-581.

32. Zarewych DM, Kindzelskii AL, Todd RF III, Petty HR. LPS induces CD14 association with complement receptor type 3, which is reversed by neutrophil adhesion. J Immunol 1996; 156: 430-433.

33. Juffermans NP, Dekkers PE, Peppelenbosch MP, Speelman $P$, van Deventer SJ, van der Poll T. Expression of the chemokine receptors CXCR1 and CXCR2 on granulocytes in human endotoxemia and tuberculosis: involvement of the p38 mitogen-activated protein kinase pathway. J Infect Dis 2000; 182: 888-894.

34. Myhre O, Andersen JM, Aarnes H, Fonnum F. Evaluation of the probes 2',7'-dichlorofluorescin diacetate, luminol, and lucigenin as indicators of reactive species formation. Biochem Pharmacol 2003; 65: 1575-1582.

35. Klink M, Brzychcy M, Ziolkowski A, Swierzko A, Sulowska $Z$, Cedzynski M, et al. The comparison of some biological activities of lipopolysaccharides obtained from smooth and rough Proteus mirabilis strains. Acta Microbiol Pol 1998; 47: 141-151.

36. Jesch NK, Dorger M, Enders G, Rieder G, Vogelmeier C, Messmer $\mathrm{K}$, et al. Expression of inducible nitric oxide synthase and formation of nitric oxide by alveolar macrophages: an interspecies comparison. Environ Health Perspect 1997; 105 (Suppl 5): 1297-1300. 